\title{
Estimation of Hourly Sea Surface Salinity in the East China Sea Using Geostationary Ocean Color Imager Measurements
}

\author{
Dae-Won Kim ${ }^{1}$, Young-Je Park ${ }^{2}$, Jin-Yong Jeong ${ }^{2}$ and Young-Heon Jo ${ }^{1, *(\mathbb{D})}$ \\ 1 Department of Oceanography, Pusan National University, Geumjeong-Gu, Busan 46241, Korea; \\ daewon@pusan.ac.kr \\ 2 Korea Institute of Ocean Science and Technology, Busan 49111, Korea; youngjepark@kiost.ac.kr (Y.-J.P.); \\ jyjeong@kiost.ac.kr (J.-Y.J.) \\ * Correspondence: joyoung@pusan.ac.kr; Tel.: +82-51-510-3372
}

Received: 23 January 2020; Accepted: 22 February 2020; Published: 25 February 2020

\begin{abstract}
Sea surface salinity (SSS) is an important tracer for monitoring the Changiiang Diluted Water (CDW) extension into Korean coastal regions; however, observing the SSS distribution in near real time is a difficult task. In this study, SSS detection algorithm was developed based on the ocean color measurements by Geostationary Ocean Color Imager (GOCI) in high spatial and temporal resolution using multilayer perceptron neural network (MPNN). Among the various combinations of input parameters, combinations with three to six bands of GOCI remote sensing reflectance (Rrs), sea surface temperature (SST), longitude, and latitude were most appropriate for estimating the SSS. According to model validations with the Soil Moisture Active Passive (SMAP) and Ieodo Ocean Research Station (I-ORS) SSS measurements, the coefficient of determination $\left(R^{2}\right)$ were 0.81 and 0.92 and the root mean square errors (RMSEs) were $1.30 \mathrm{psu}$ and $0.30 \mathrm{psu}$, respectively. In addition, a sensitivity analysis revealed the importance of SST and the red-wavelength spectral signal for estimating the SSS. Finally, hourly estimated SSS images were used to illustrate the hourly CDW distribution. With the model developed in this study, the near real-time SSS distribution in the East China Sea (ECS) can be monitored using GOCI and SST data.
\end{abstract}

Keywords: sea surface salinity estimation; Changiiang diluted water; neural network; GOCI application; ocean color

\section{Introduction}

The Changjiang Diluted Water (CDW) discharge influences the maritime environment, not only in the East China Sea (ECS), but also in Korean coastal regions including the Jeju Island coastal regions (Figure 1) [1-9]. Especially, the CDW is strengthened by high precipitation in the East China region in the summer season [10-12]. During summer season, high solar radiation heats the surface water and enhances the upper ocean stratification via high sea surface temperature (SST) and low sea surface salinity (SSS) [9]; this can damage aquaculture via anomalous marine environmental conditions. For example, in the summer of 2016, an anomalously large CDW caused approximately \$9 million in economic damage to Korean aquaculture by enhancing the stratification via low SSS and high SST [13] (pp. 1-2). In the ECS, regular SSS observation has been consistently conducted at stationary points, the Ieodo Ocean Research Station (I-ORS) (Figure 1), and the shipboard observation by Korean National Institute of Fisheries Science serial oceanographic observation. However, such spatio-temporally limited surveys make it difficult to determine the exact spatial and temporal CDW distribution and its paths. 
Accordingly, satellite sensor measurements are useful to understand the features of the CDW and its extension into the surrounding regions. The space borne SSS datasets are currently available through the Soil Moisture and Ocean Salinity (SMOS) and Soil Moisture Active Passive (SMAP) missions, which have global coverage. However, these two sensors have limitations for observing near-real time SSS variations in coastal regions because those microwave measurements have coarse spatial resolutions (30-100 km), low revisit frequencies (three days or longer), and experience land contamination [14-19]. Moreover, SMAP product has the issues of radio-frequency interference (RFI) in the ECS [20]. Therefore, an accurate investigation of the SSS near coastal regions is needed to understand the variations and distribution of the CDW [21].

To continuously monitor the SSS distribution along coastal regions, ocean color measurements have been used in various coastal regions [22-28]. Some studies have primarily applied the relationship between the SSS and the colored dissolved organic matter (CDOM) in different regions, such as the Clyde Sea [23], the ECS [6,25,26], and Osaka Bay in Japan [21]. A large portion of the CDOM is caused by river plumes originating from terrestrial sources and is associated with fresh water. The freshwater from river plumes has a low reflectance for blue wavelengths due to the absorption of blue wavelengths by the CDOM; this feature allows for the detection of CDOM using optical sensors. The relationship between the CDOM and the salinity indicates that low salinity conditions are expected when the CDOM concentration is high. However, the relationships between the CDOM optical properties and the SSS reported in previous studies have varied in space and time due to local river characteristics and their seasonalities $[6,29]$. In addition, the relationship between the CDOM optical properties and the salinity can be different even in the same region because the CDOM can be changed, not only by salinity, but also by other factors, such as the chlorophyll concentration and suspended sediment type differences $[18,22,24]$.

To overcome such limitations, Geiger et al. [18] used a neural network (NN) approach to estimate the SSS in the coastal Mid-Atlantic region using marine environmental variables and ocean color measurements. The strengths of a NN approach are that the assumptions made by calculating the CDOM from optical signals are not required, and that the inclusion of other parameters, such as SST, is possible. Indeed, they demonstrated that the SST is an essential parameter to estimate the SSS in four different coastal regions (the coastal Mid-Atlantic region, the Chesapeake and Delaware bays, and the Hudson Estuary). In addition, Chen and Hu [19] estimated the SSS from ocean color and SST measurements using a multilayer perceptron neural network (MPNN) in the northern Gulf of Mexico after extensive evaluations testing many other empirical approaches (i.e., principle component analysis, multi-nonlinear regression, decision tree, random forest, and supporting vector machines). They demonstrated the robustness of their MPNN model for estimating the SSS using the input errors. Because the CDW is highly correlated with the SST in the ECS in the summer season [9], an MPNN approach was used in this study instead of a CDOM approach in order to use the SST measurement. The importance of SST is discussed via an evaluation of the model performance in this study.

The highest spatial and temporal resolution ocean color sensor measurements available in the ECS are those of the Geostationary Ocean Color Imager (GOCI) with spatial and temporal resolutions of $500 \mathrm{~m} \times 500 \mathrm{~m}$ and eight times per day, respectively [30,31]. Compared to polar orbiting satellite ocean color products, GOCI has an advantage for monitoring the CDW distribution because it observes the same area eight times per day with high spatial resolution. Therefore, GOCI data were used to develop the SSS estimation model and produce SSS images in the ECS. Liu et al. [27], Nakada et al. [21], and Sun et al. [28] attempted to analyze the SSS using GOCI remote sensing reflectance (Rrs) measurements in the Bohai Sea, the Osaka Bay, and the Southern Yellow Sea (SYS), respectively. Liu et al. [27] developed a simple multi-linear statistical regression model to estimate the SSS using GOCI data. Their study demonstrated the ability of GOCI to observe the hourly SSS variability validated by the buoy measured SSS. Nakada et al. [21] estimated the SSS using a CDOM optical absorption coefficient from GOCI. Using a time series of in-situ SSS data from an automated observation system, they improved their satellite-derived SSS accuracy. Their study also compared 
a plume area before and after a typhoon period. Sun et al. [28] estimated the SSS for the month of August from 2011 to 2018 in the SYS and achieved a root mean square error (RMSE) of 0.29 psu. Nevertheless, the algorithms discussed in these studies were specific to each study region and require further validations to apply to other regions. Moreover, the three studies described above analyzed the same ocean color satellite data (GOCI) to develop their algorithms with different wavelength GOCI bands (i.e., Liu et al. [27] used Rrs490, Rrs555, and Rrs660; Nakada et al. [21] used Rrs412 and Rrs555; and Sun et al. [28] used Rrs490 and Rrs555).

Regardless of the method and sensor, previous studies used different wavelengths either in different regions or in the same region. Therefore, this study aims to test various combinations of wavelengths to develop a new model for estimating SSS using the GOCI data in the ECS. Accordingly, eight combinations of input parameters using GOCI Rrs bands 1-6, three band ratios (band 1/band 4, band 2/band 4, and band 2/band 4), and the SST were analyzed. In addition, the SMAP-derived SSS products were used as an output parameter due to the lack of available in-situ data. The accuracy of the SMAP SSS products in the ECS was evaluated using the I-ORS SSS measurements (the result is described in Section 2.1.2). Moreover, a sensitivity analysis to evaluate the importance of the input parameters was conducted to determine the relationship between each input parameter and the predicted SSS, as shown in Section 3.3. Finally, hourly SSS images generated by the proposed model are discussed in Section 4.

\section{Materials and Methods}

\subsection{Materials}

\subsubsection{GOCI Rrs Data}

Ocean color data from GOCI can be downloaded from the Korea Ocean Satellite Center website (http://kosc.kiost.ac.kr/). GOCI has six visible bands (412 nm, $443 \mathrm{~nm}, 490 \mathrm{~nm}, 555 \mathrm{~nm}, 660 \mathrm{~nm}$, and $680 \mathrm{~nm}$ ) and two near-infrared bands $(745 \mathrm{~nm}$ and $865 \mathrm{~nm})$. Because the two near-infrared bands are primarily used for atmospheric correction to GOCI, the six visible Rrs bands were used in this study. According to previous studies, not only the visible bands but also the GOCI band ratios (412 nm/555 nm (R1), $443 \mathrm{~nm} / 555 \mathrm{~nm}$ (R2), and $490 \mathrm{~nm} / 555 \mathrm{~nm}$ (R3)) can be used to estimate the SSS using ocean color measurements $[18,26,32]$. Three band ratios are used representing for the spectral shape in the blue-green portion of the spectrum, which varies with CDOM concentration [18,26,33]. GOCI L1B image covers Korea, Japan, the eastern coast of China, and parts of the northern coast of Taiwan $(2500 \mathrm{~km} \times 2500 \mathrm{~km})$ and is composed of 16 subimages called slots [34]. A part of GOCI images, slot number 9 and 10 covering ECS, Chanjiang River mouth, Jeju Island, and the south coast of Korea are used in this study.

\subsubsection{I-ORS Data}

The I-ORS is located at the boundary between the Yellow Sea and the ECS $\left(125.18^{\circ} \mathrm{E} 32.12^{\circ} \mathrm{N}\right)$, and the CDW frequently passes through this location (Figure 1). Due to the favorable geographical location of the I-ORS, various oceanic, metrological, and coastal studies have been conducted using measurements at I-ORS [35,36]. The I-ORS salinity data used in this study were measured at various depths ( $3 \mathrm{~m}, 5 \mathrm{~m}, 10 \mathrm{~m}, 15 \mathrm{~m}, 20 \mathrm{~m}, 30 \mathrm{~m}$, and $40 \mathrm{~m})$ with sampling intervals of $1 \mathrm{~min}$. To match the SMAP data, 3-m depth salinity data were used after daily averaging (or sampling). During the study period (the year of 2016), 141 days of SSS data were available (April-October). These data were used to evaluate the accuracy of the SSS data from SMAP and the performance of the developed algorithm.

\subsubsection{Group for High Resolution Sea Surface Temperature (GHRSST) SST Data}

In addition to the GOCI Rrs data, SST data were also used as input variables for the algorithm to estimate the SSS. SST data have been used in previous studies to estimate the SSS using the NN 
approach [18,19]; however, the influence of the SST on the SSS is not clearly understood. Therefore, algorithms trained with or without SST were compared to evaluate the impact of the SST on the SSS. In this study, the GHRSST level 4 data were used to train the NN model. This measurement produces a $0.01^{\circ} \times 0.01^{\circ}$ spatial resolution and a daily temporal resolution. The GHRSST data are available on the GHRSST website (https://www.ghrsst.org/). The GHRSST level 4 gridded products are generated by combining complementary satellite and in-situ observations within optimal interpolation systems. The differences in the validation results when training with or without SST are discussed in this paper.

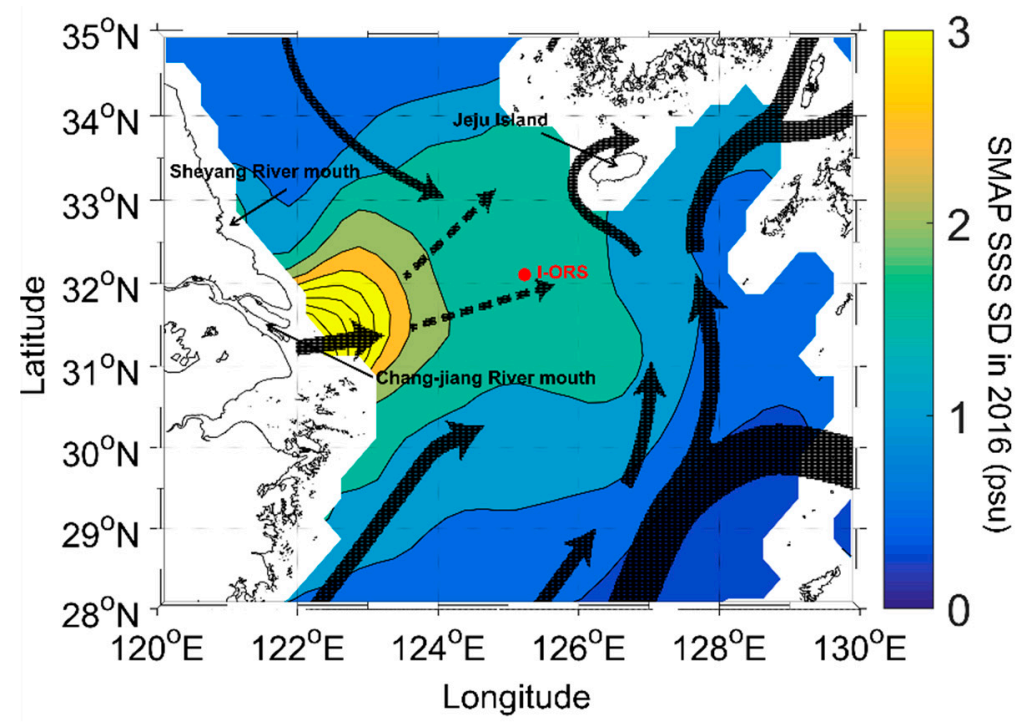

Figure 1. Soil Moisture Active Passive (SMAP) standard deviation (SD) of sea surface salinity (SSS) in 2016. Black arrows indicate typical ocean currents during summer season from 2002 to 2005 in this region (provided by Korea Hydrographic and Oceanographic Agency). Location of Ieodo Ocean Research Station (I-ORS) is marked with a solid red circle. Regions of more than 1 psu of SD were chosen to train multilayer perceptron neural network (MPNN) algorithm.

\subsubsection{SMAP Data}

Even though the primary mission of SMAP is to measure the soil moisture, the L-band radiometer of the SMAP platform can be used to measure the SSS in the global ocean. In this study, the version 4.0 of SMAP level 3 was used (http://www.remss.com/missions/smap/salinity/). The RFI was filtered in the version 4.0 of SMAP product. The SMAP level 3 product is provided with a $25-\mathrm{km}$ spatial resolution and a daily temporal resolution (8-day running average). The near-polar orbits of SMAP cover the global oceans in 3 days with a repeat cycle of 8 days. To verify the SMAP performance, a validation with 8-day running averaged I-ORS data was conducted (Figure 2). The scatter diagram in Figure 2 shows the relationship between the SSS from I-ORS and that from SMAP with a coefficient of determination $\left(\mathrm{R}^{2}\right)$ of 0.71 and an RMSE of $1.02 \mathrm{psu}$. The SSS from SMAP agreed well with the I-ORS measurement compared to previous results (RMSE of approximately 3 psu near the Changjiang River mouth) obtained by Wu et al. [37]. Using this relationship, the SMAP SSS in the ECS could be correlated to the output parameter of the MPNN model despite it not being an in-situ measurement. 


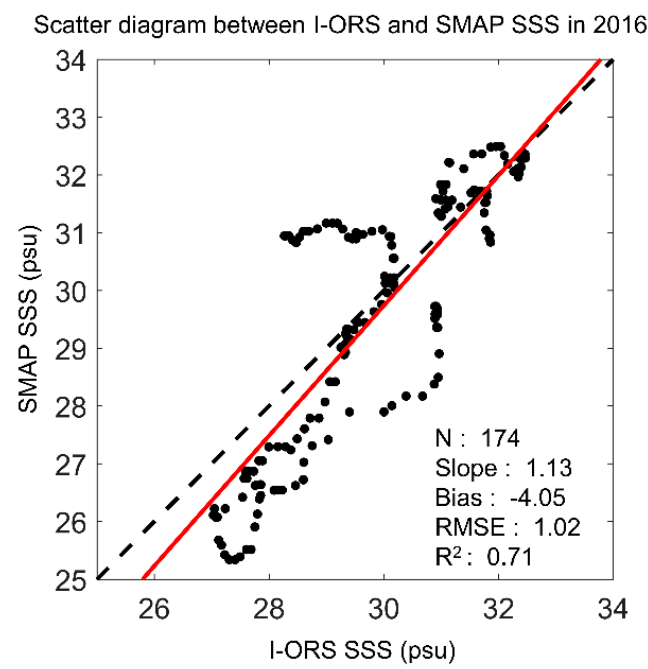

Figure 2. Scatter diagram between I-ORS and SMAP SSS in 2016.

\subsection{Methods}

\subsubsection{GOCI Data Preprocessing}

To reduce the noise contamination of the GOCI Rrs data, two analyses were conducted. First, Lee et al.'s [38] suspended particulate matter (SPM) speckle removing method was applied. This methodology effectively eliminated unexpected noise and some extremely high or low SPM values. Second, a novel quality assurance (QA) system was included [39]. The QA system was applied by measuring the Rrs data quality as a score between 0 and 1, with 1 indicating a perfect Rrs spectrum and 0 indicating an unusable Rrs spectrum. In this study, a QA score under 0.5 was treated as an error and removed. Following these two steps, the GOCI error was significantly decreased for the GOCI SSS images compared to the error obtained before preprocessing the SSS images.

\subsubsection{MPNN}

When developing the MPNN, a back-propagation learning technique with adaptive moment estimation (Adam) optimization and Rectified Linear Unit (ReLU) activation function were implemented in TensorFlow [40]. Figure 3 shows an example of an MPNN schematic diagram, which is composed of the inputs and the hidden and output layers. The training process was conducted 5000 times to improve the accuracy by adjusting the weights and biases of connections by changing the numbers of neurons and hidden layers. Table 1 shows detailed information concerning the training of the MPNN. All datasets were randomly divided into training (80\%) and validation (20\%) datasets in the training period. $\mathrm{R}^{2}$ and RMSE were calculated using the validation dataset, which was an independent from the training dataset. All input parameters were normalized before train.

Since detection of low salinity water mass is important, the network was trained and validated with as many relatively low salinity conditions as possible. In the summer of 2016, a large amount of freshwater from the Changjiang River plume was observed [9,13,41]. Therefore, the year 2016 was selected as a study period when relatively low SSS covered wide regions in the ECS. The first attempt to train the MPNN was made using all pixels of slots 9 and 10 of the GOCI products. However, the training result showed a bias toward relatively high SSS ranges (33-35 psu), which are normal salinity conditions. Therefore, the training datasets were re-chosen, where the standard deviation (SD) of the SMAP SSS was more than 1 psu to prevent the MPNN from biasing relatively high SSS. Figure 1 shows the SD of the SMAP SSS in 2016 and reveals the frequently CDW-affected regions. 


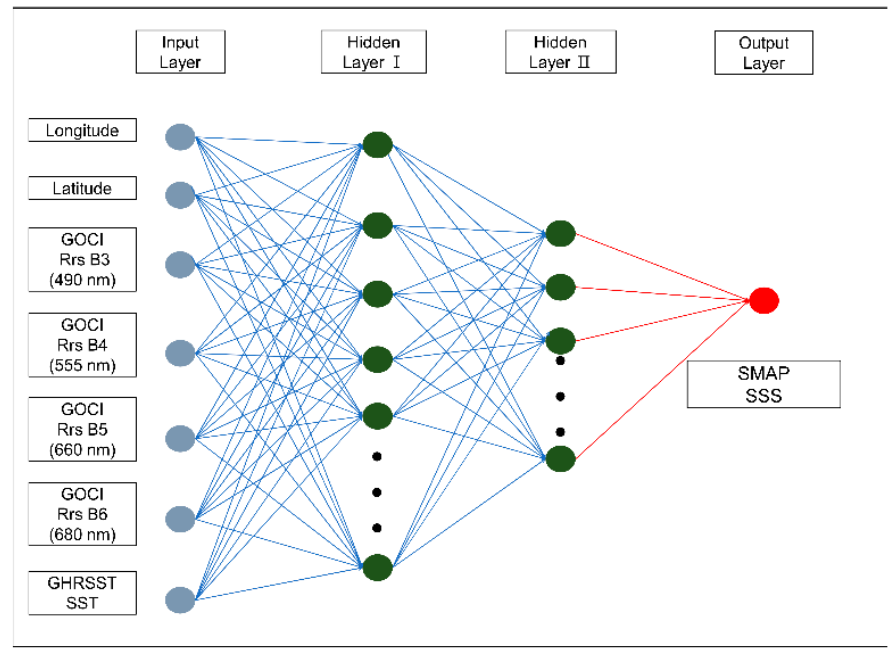

Figure 3. An example of a schematic diagram of the MPNN using D3 (longitude, latitude, Rrs490, Rrs555, Rrs660, Rrs680, and SST), consisting of input, hidden, and output layers. The number of neurons were different with dataset (Table 1).

Table 1. Detail training information of optimized multilayer perceptron neural network (MPNN).

\begin{tabular}{ccccc}
\hline Input dataset & Train $\mathbf{R}^{\mathbf{2}}$ & Train RMSE (psu) & Validation R & Validation RMSE (psu) $^{\mathbf{2}}$ \\
\hline Bands 3 to 6 (D1) & 0.75 & 1.73 & 0.68 & 1.73 \\
Bands 3 to 6 and R3 (D2) & 0.87 & 1.10 & 0.67 & 1.73 \\
Bands 3 to 6 and SST (D3) & 0.85 & 1.15 & 0.81 & 1.30 \\
Bands 3 to 6, R3, and SST (D4) & 0.87 & 1.10 & 0.76 & 1.51 \\
Bands 1 to 6 (D5) & 0.81 & 1.44 & 0.67 & 1.74 \\
Bands 1 to 6, R1, R2, and R3 (D6) & 0.79 & 1.50 & 0.63 & 1.92 \\
Bands 1 to 6 and SST (D7) & 0.85 & 1.28 & 0.79 & 1.39 \\
Bands 1 to 6, R1, R2, R3, and SST (D8) & 0.85 & 1.15 & 0.33 \\
\hline
\end{tabular}

In this study, eight different combinations of input parameters (longitude, latitude, Rrs bands 1 (412 nm)-6 (680 nm), R1, R2, R3, and SST) were used to develop the MPNN model, and schematic diagram of one example network is illustrated in Figure 3. The eight input datasets D1-D8 are defined as follows: D1 consists of Rrs bands 3-6; D2 consists of Rrs bands 3-6 and R3; D3 consists of Rrs bands 3-6 and SST; D4 consists of Rrs bands 3-6, R3, and SST; D5 consists of Rrs bands 1-6; D6 consists of Rrs bands 1-6, R1, R2, and R3; D7 consists of Rrs bands 1-6 and SST; and D8 consists of Rrs bands 1-6, R1, R2, and R3, and SST, and all datasets include the longitude and latitude (Table 1). Out of daily SMAP SSS images from January 1, 2016, to December 31, 2016, every four-day images (92 images) are used for training and the remaining 274 images were used to validate the output of the MPNN.

\section{Results}

\subsection{Model Performance Compared to SMAP SSS}

Figure 4 shows scatter diagrams between the MPNN results and the SMAP SSS for validation data with the eight different input datasets (D1-D8). Noticeable differences are observed with and without SST in the input datasets. In the case of input datasets without SST (Figure $4 a, b, e$ and f), $R^{2}$ is lower and RMSE is larger than for input datasets with SST (Figure 4c,d,g and h) by approximately 0.13 and $0.40 \mathrm{psu}$, respectively. Conversely, the inclusion of band ratios (Figure $4 \mathrm{~b}, \mathrm{~d}, \mathrm{f}$ and $\mathrm{h}$ ) did not improve the model performance compared to the inclusion of SST. It appears that the SST is significantly related to the SSS in this region. A comparison between the four-band group (Figure 4a-d) and the six-band group (Figure $4 \mathrm{e}-\mathrm{h}$ ) performances reveal no significant differences. This result indicates that the blue-wavelength (bands 1 and 2 of GOCI) spectral signals are not important parameters for 
estimating the SSS. Of the eight different scatter diagrams in Figure 4, the D3 dataset result shows the best performance ( $R^{2}$ of 0.81 and RMSE of $\left.1.30 \mathrm{psu}\right)$.

In addition, Figures 5 and 6 show maps of $R^{2}$ and RMSE between the predicted SSS and the SMAP SSS. Notably, in these two figures, the overall performance increased when including SST; this is shown clearly in Figure 5. Without SST (D1, D2, D5, and D6), the $\mathrm{R}^{2}$ values in the western and eastern areas were under 0.8 and 0.4 , respectively. However, including SST, the $\mathrm{R}^{2}$ values of the overall regi- on were approximately 0.8 , except near the Sheyang River mouth region (in the northwestern part of the study area, see Figure 1). The eastern part of the study area includes the Kuroshio Current, which has high SST and SSS. Moreover, the Kuroshio Current system is known to have a high SST and SSS water type. Therefore, including the SST could improve the model for the SSS estimation in the overall region, especially in the eastern part of the study area.
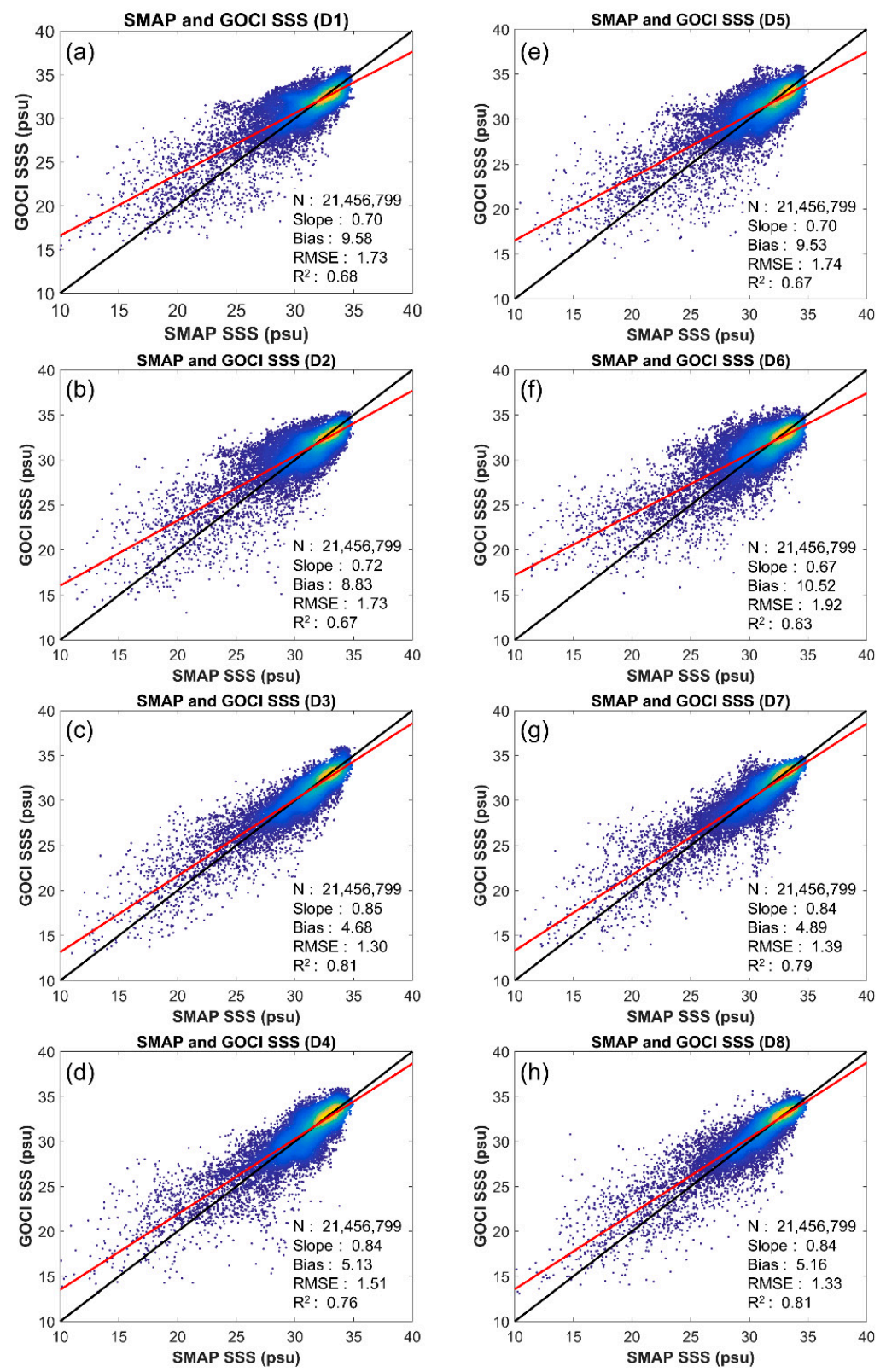

Figure 4. Density scatter diagram between SMAP and Geostationary Ocean Color Imager (GOCI) SSS estimated by (a) D1, (b) D2, (c) D3, (d) D4, (e) D5, (f) D6, (g) D7, and (h) D8 input dataset. Color indicates scatter density. 

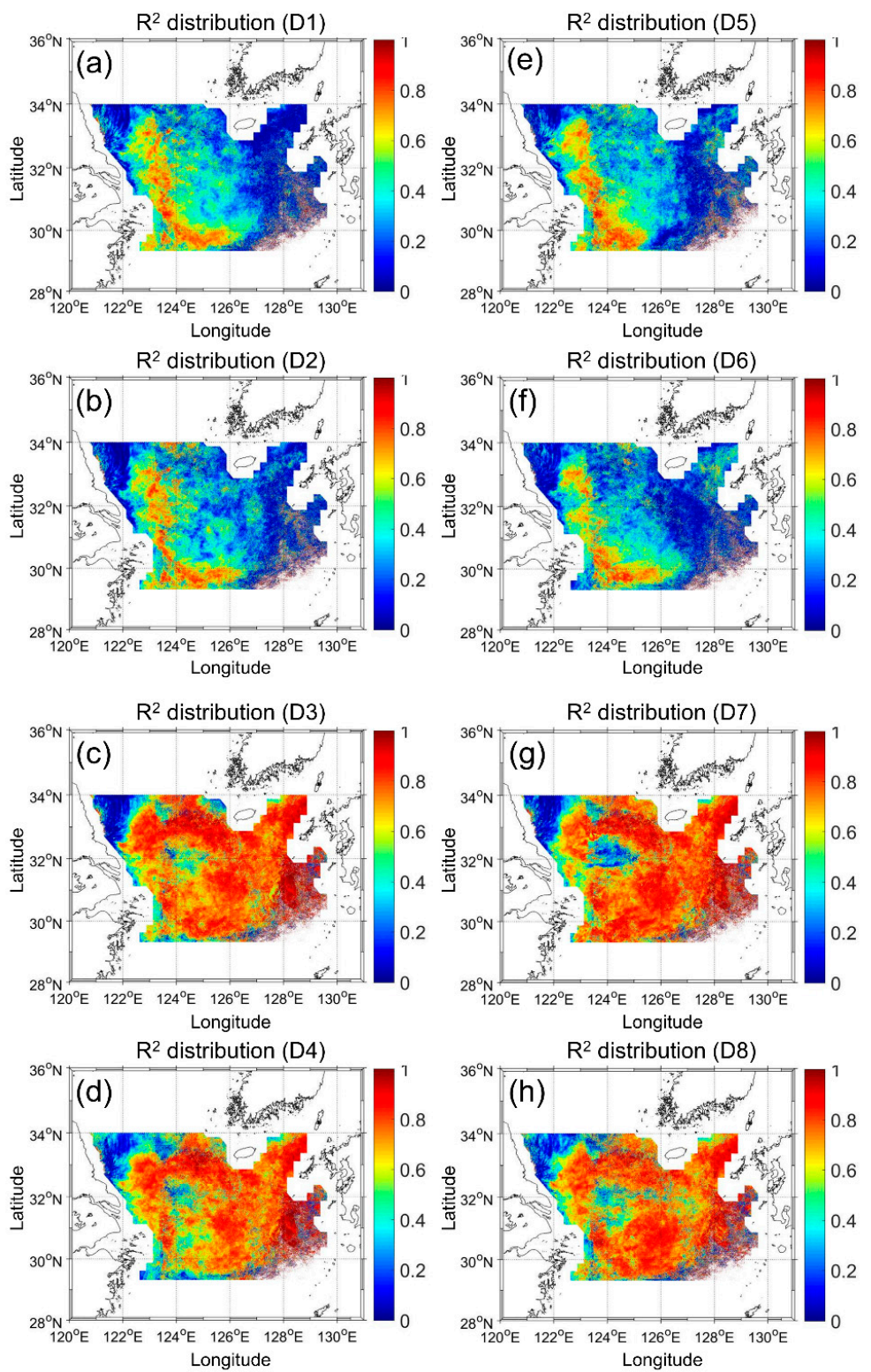

Figure 5. Coefficient of determination $\left(R^{2}\right)$ maps between SMAP and GOCI SSS estimated by (a) D1, (b) D2, (c) D3, (d) D4, (e) D5, (f) D6, (g) D7, and (h) D8 input dataset.

More detailed differences are found in Figure 6. Every panel in Figure 6 has relatively high RMSE values between the SMAP and predicted SSS near the Changiiang River mouth region. However, the areas near the Sheyang River mouth region, the southwestern area of Jeju Island, and the Kuroshio Current region (the southeastern part of the study area) show different RMSE features in the eight RMSE maps. In the cases that do not include the SST in the input datasets (Figure 6a,b,e and f), relatively high RMSE values are seen in the southwestern area of Jeju Island and the Kuroshio Current region. Conversely, the RMSE is decreased when including the SST as an input parameter in this area (Figure $6 c, d, g$, and h). Of the four RMSE maps including SST (Figure $6 c, d, g$, and h), the D3 dataset result shows the relatively good RMSE distribution (Figure 6c). Near the Sheyang River mouth region, the four-band group (Figure $6 \mathrm{a}, \mathrm{b}, \mathrm{c}$ and d) and six-band group (Figure 6e,f,g and h) show opposite features when including the band ratios and SST. The four-band group shows small changes in the RMSE due to the inclusion of just the band ratio (R3) or the SST (Figure 6b,c, respectively); however, when including both the band ratio and the SST, the RMSE is increased notably in this region (Figure 6d). Conversely, the inclusion of the three band ratios and the SST decreased the RMSE of the 
six-band group (Figure 6h), while the individual parameters (the band ratios or SST) increased the RMSE in this region (Figure $6 \mathrm{f}, \mathrm{g}$, respectively). Similar to the spatial pattern changes of the $\mathrm{R}^{2}$ image caused by different input datasets (Figure 5), the RMSE decreased overall in the study area when using the SST as an input parameter. The decrease in the RMSE was remarkable west of the Jeju Island area and the Kuroshio Current region. The RMSE results when including the SST and band ratios show an opposite effect for the four-band group (Figure $6 \mathrm{c}, \mathrm{d}$ ) and the six-band group (Figure $6 \mathrm{~g}, \mathrm{~h}$ ). In Figure $6 \mathrm{~d}$, RMSE increased compared to Figure $6 \mathrm{c}$ near the Sheyang River mouth and in the eastern parts of the study regions. Conversely, the SST and the three band ratios improve the MPNN performance in the six-band group (Figure 6g,h) near the Sheyang River mouth and around the $124^{\circ} \mathrm{E} 32.5^{\circ} \mathrm{N}$ area. By including SST in the input dataset, the MPNN performances ( $R^{2}$ and RMSE) improved significantly in the overall study region (Figures 4-6). Therefore, SST is an important parameter for estimating the SSS in this study.
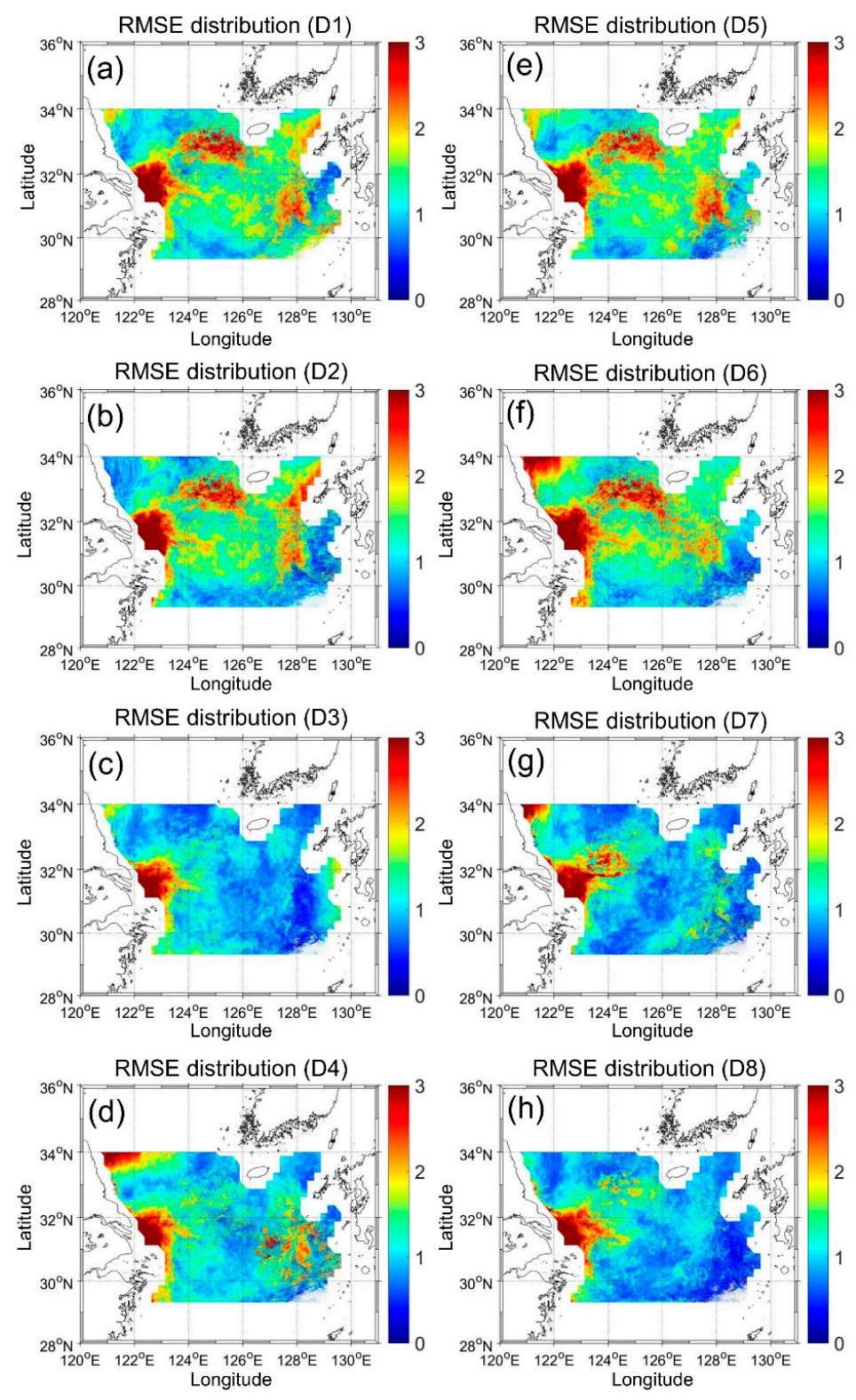

Figure 6. Root mean square error (RMSE) maps between SMAP and GOCI SSS estimated by (a) D1, (b) D2, (c) D3, (d) D4, (e) D5, (f) D6, (g) D7, and (h) D8 input dataset. 


\subsection{Model Performance Compared to I-ORS SSS}

Figure 7 shows scatter plots of the validation with the I-ORS SSS measurements in 2016. Of the 141 days from April 30 to October 1, 8 days were validated due to the GOCI data availability over the I-ORS during this period. Even though only 8 days were validated, the performance of the MPNN varied with the eight different input datasets. The ranges of $\mathrm{R}^{2}$ and RMSE were 0.58-0.94 and 0.25-0.88 psu, respectively. Of the eight datasets, D3, D4, and D7 had $\mathrm{R}^{2}$ values of more than 0.90 and RMSE values of less than $0.35 \mathrm{psu}$ (Figure $7 \mathrm{c}, \mathrm{d}$ and g). Even though the D7 dataset results show the best performance for I-ORS (Figure $7 \mathrm{~g}$ ), the $\mathrm{R}^{2}$ and RMSE distributions of the overall study area indicate that the MPNN model with D3 performs better than that with D7. The developed MPNN model has an impressive performance compared to previous studies that estimated the SSS using GOCI. $\mathrm{R}^{2}$ value of the SSS estimation model from Liu et al. [27] was 0.795. Nakada et al. [21] estimated the SSS using GOCI in Osaka Bay and achieved $R^{2}$ of 0.57 and RMSE of $1.5 \mathrm{psu}$. Even though the SSS estimation model developed by Sun et al. [28] had a relatively low RMSE ( $0.29 \mathrm{psu})$, its $\mathrm{R}^{2}$ value was 0.62 . In comparison to these three studies, the performance of the MPNN model with D3 has a relatively high $R^{2}(0.92)$ and low RMSE ( $0.30 \mathrm{psu}$ ). Therefore, the MPNN model using the GOCI and SST data successfully estimated the SSS near the I-ORS regions.
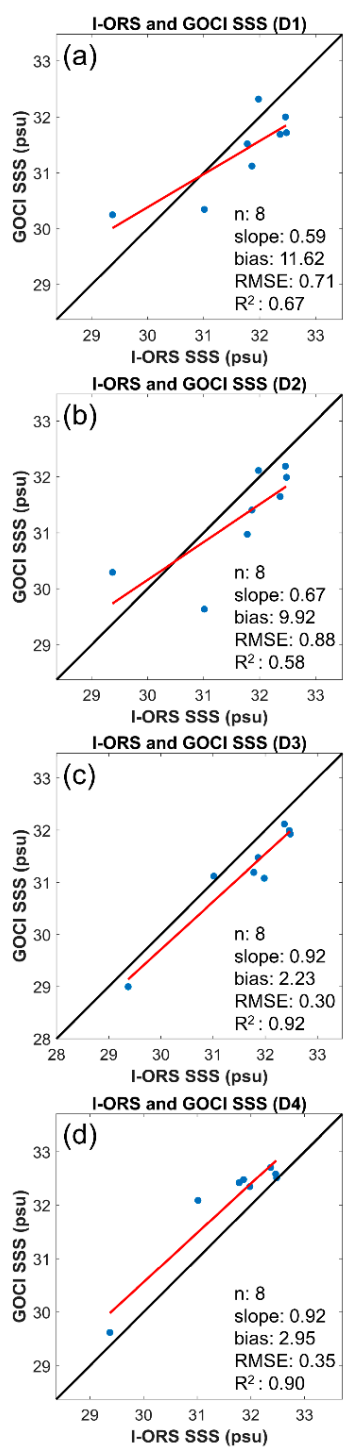
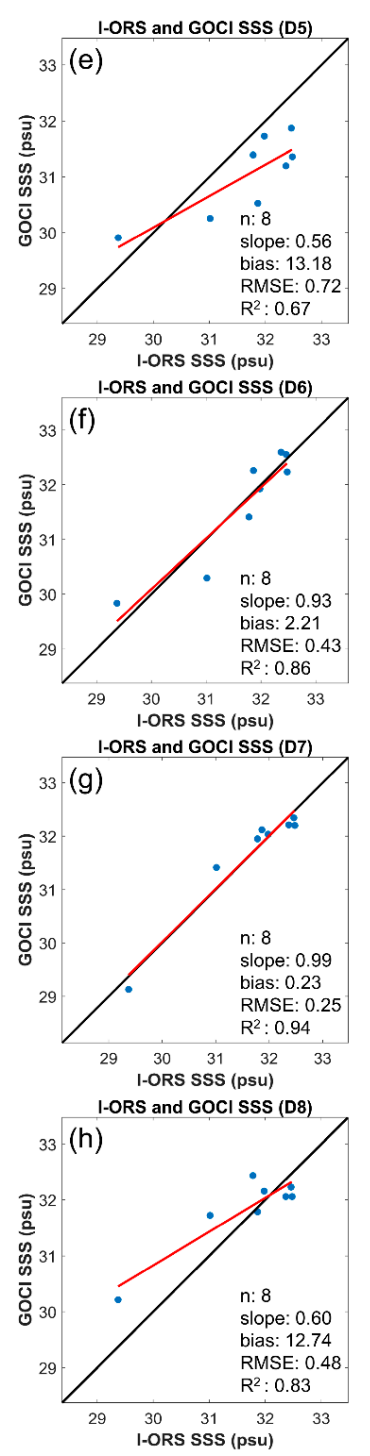

Figure 7. Scatter diagrams between I-ORS and GOCI SSS estimated by (a) D1, (b) D2, (c) D3, (d) D4, (e) D5, (f) D6, (g) D7, and (h) D8 input dataset. 


\subsection{Importance of Input Parameters}

The MPNN validation results were described using four different approaches (validation with SMAP, $\mathrm{R}^{2}$ and RMSE maps, and validation with I-ORS). Consequently, the MPNN training with the D3 dataset (longitude, latitude, Rrs490, Rrs555, Rrs660, Rrs680, and SST) was used to determine the SSS estimation model. Even though the D7 result was better than the D3 result for the validation with I-ORS (Figure 7), the D7 result had a relatively high RMSE near the Sheyang River mouth and the ECS (around $124^{\circ} \mathrm{E} 32.3^{\circ} \mathrm{N}$ ) compared to the D3 result in Figure 6. To understand the importance of the input parameters for the SSS estimation, a sensitivity analysis was conducted. Instead of analyzing the sensitivity analysis for the entire region, the location of I-ORS was chosen because the CDW passes through this location frequently. Figure 8 shows the sensitivity analysis results for the five input parameters at the I-ORS location. The analysis was conducted by changing one parameter from the minimum to the maximum of its real value while fixing the other four parameters at their mean values. For example, the blue line indicates the sensitivity of Rrs490 for the SSS estimation when the other parameters were constant (at their mean values at the I-ORS, i.e., Rrs490: 0.0110, Rrs555: 0.0107, Rrs660: 0.0046, Rrs680: 0.0043 , and SST: $19.97^{\circ} \mathrm{C}$ ). According to Figure 8, a relatively high SSS ( $>34 \mathrm{psu}$ ) was associated with high Rrs660 values (orange line) and a relatively low SSS ( $<28 \mathrm{psu}$ ) was associated with high Rrs680 (red line); the middle range of the SSS (28-34 psu) was adjusted using all of the input parameters. The SSS variability shows positive relationships with Rrs490 and Rrs660 and negative relationships with Rrs555, Rrs680, and SST. The sensitivity analysis results show the significance of the red-wavelength spectral signal at I-ORS. This result is different from those of other previous studies that did not include red-wavelength signals in their algorithms [6,21,23,25-28]. In addition to the significance of SST, the importance of the red-wavelength spectrum signal for the SSS estimation is implied from this result.

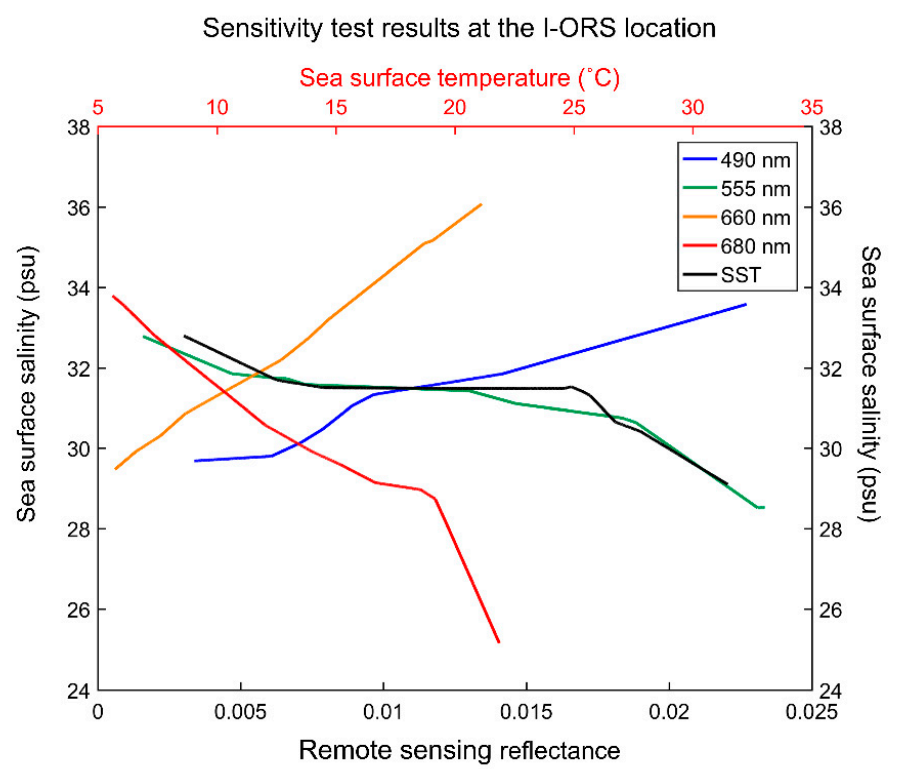

Figure 8. Sensitivity analysis results at the I-ORS location. Each line reveal the influence of input parameter on SSS variability with fixing the other parameters as mean value of real data(Rrs490: 0.0110, Rrs555: 0.0107, Rrs660: 0.0046, Rrs680: 0.0043, and SST: $\left.19.97^{\circ} \mathrm{C}\right)$.

\subsection{Validation of the GOCI SSS}

The model developed in this study enables the SSS distribution to be monitored with high spatial and temporal resolution using GOCI and SST measurements in the ECS. Figure 9 shows the monthly distribution of the SSS in 2016 as estimated by SMAP. The monthly SMAP SSS map shows that the SSS distribution in the ECS and the adjacent seas around the Korean Peninsula are primarily affected by 
the CDW in the summer season. However, SMAP SSS has coarse spatial scale $(25 \mathrm{~km})$ SSS distribution despite CDW extension revealed more detail shape and pattern in the past studies [26,42]. Conversely, the monthly GOCI SSS maps represent the SSS variability at small scales (500 m) as well (Figure 10). In this figure, intricate relatively low SSS features are observed even in the monthly averaged SSS images. In addition, Figure 11 shows a time series of three different SSS measurements at the I-ORS location. The SMAP and I-ORS SSS represent relatively low SSS conditions during the summer season. Even though the GOCI SSS did not observe this location during July and August, the overall pattern reveals a good agreement with the SMAP and I-ORS SSS. In addition, the model shows a reasonably good performance at the I-ORS location and is capable of detecting and monitoring the SSS in the ECS.
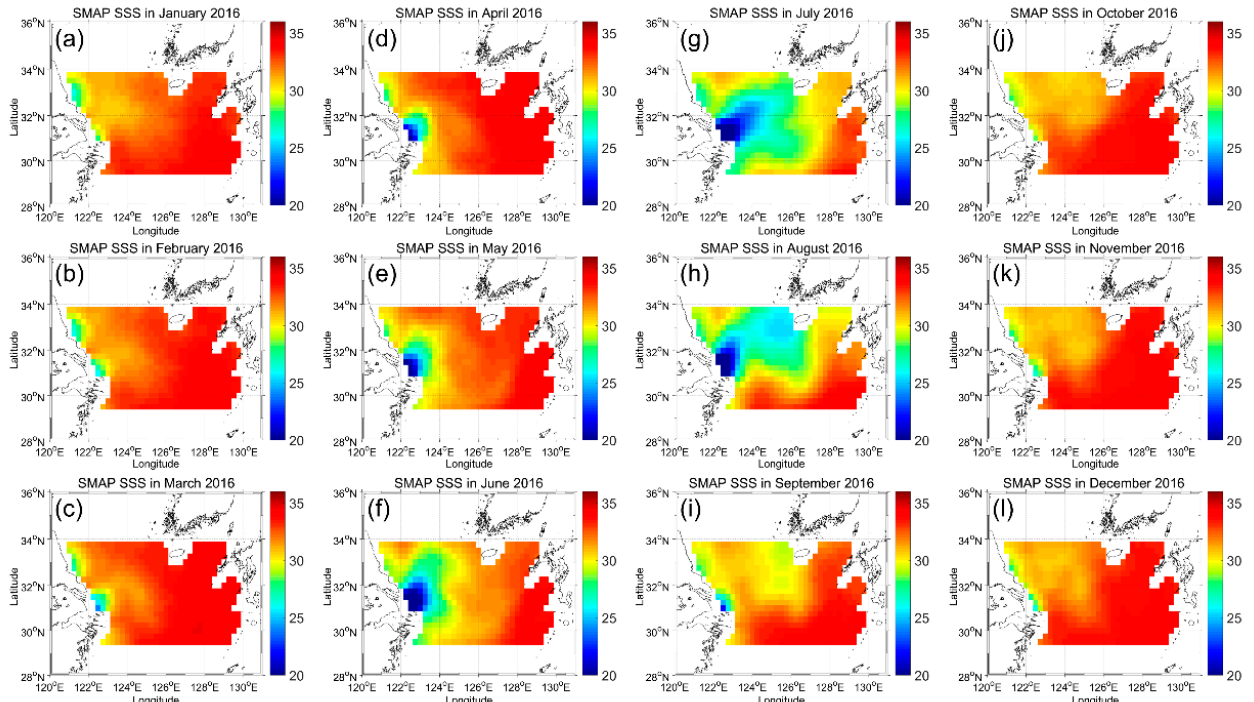

Figure 9. Monthly SSS map of SMAP in (a) January, (b) February, (c) March, (d) April, (e) May, (f) June, (g) July, (h) August, (i) September, (j) October, (k) November, and (1) December 2016. The Changjiang Diluted Water (CDW) was extended to Jeju Island in the summer season.
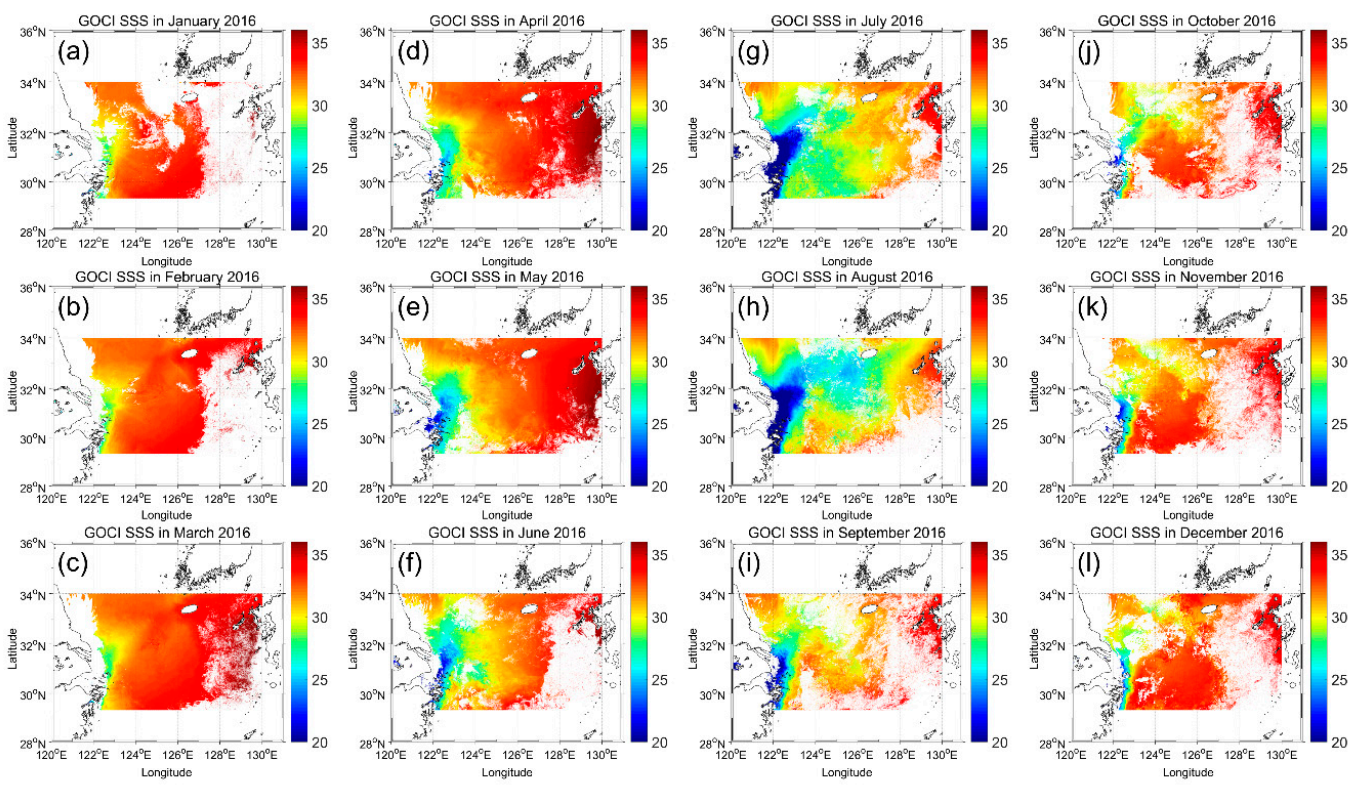

Figure 10. Monthly SSS map of GOCI in (a) January, (b) February, (c) March, (d) April, (e) May, (f) June, (g) July, (h) August, (i) September, (j) October, (k) November, and (1) December. General SSS patterns are similar to those of monthly SMAP images, but more specific features are revealed due to high spatial resolution. 


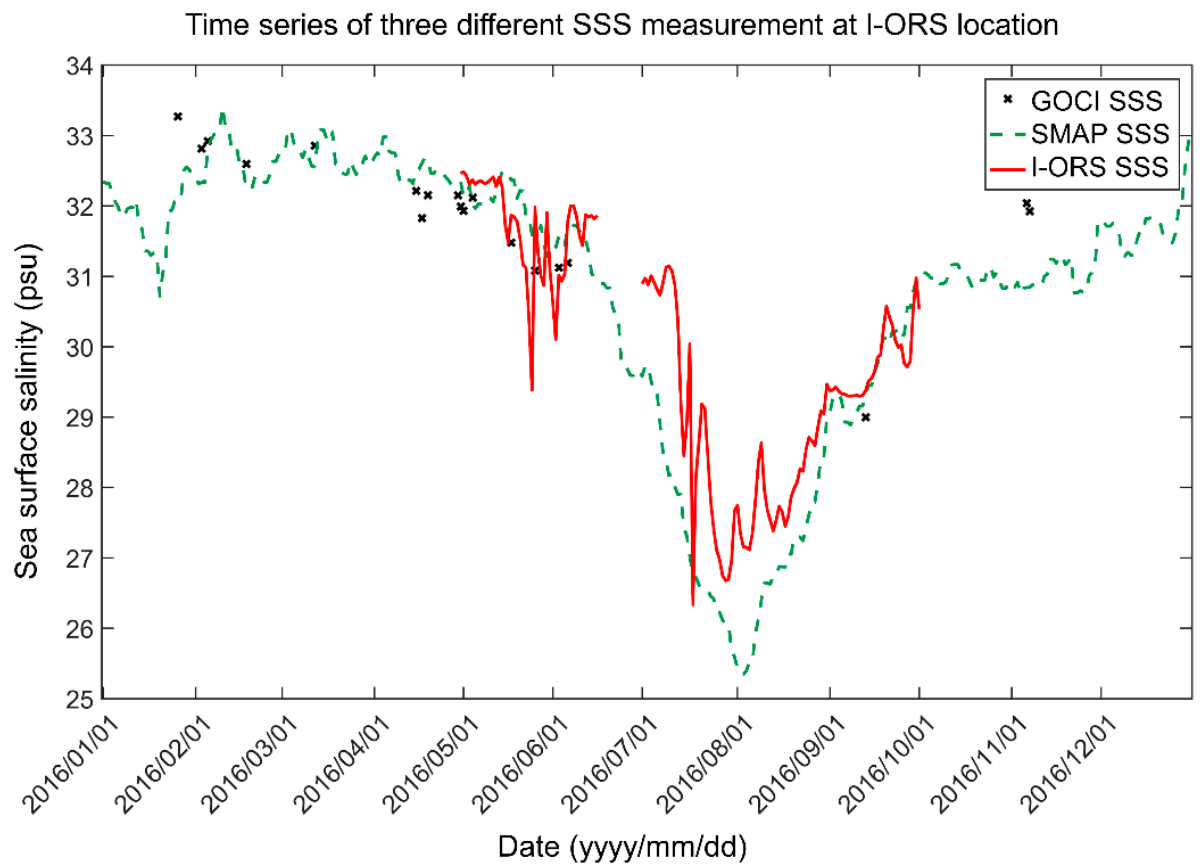

Figure 11. Time series of three different SSS measurement at I-ORS location. Overall patterns of three measurement are very similar.

\section{Discussion}

Eight different MPNN models were trained and validated in this study. The model developed using the D3 dataset showed the optimum performance. The overall model performances were an $R^{2}$ of 0.81 and an RMSE of $1.30 \mathrm{psu}$ for SSS ranges between $1 \mathrm{psu}$ and $36 \mathrm{psu}(\mathrm{N}=21,269,124)$. In comparison to other studies, the MPNN model developed in this study shows a similar performance to the results from Chen and $\mathrm{Hu}$ [19] ( $\mathrm{R}^{2}$ of 0.86 and RMSE of $1.2 \mathrm{psu}$ in the northern Gulf of Mexico) and a better performance than that of Geiger et al. [18] (RMSE of 1.40-2.29 psu). In Figure 5c, the $R^{2}$ values demonstrates the good agreement of the model with the SMAP SSS, except in the northwestern part of the study region (the Sheyang River mouth region). The relatively low $R^{2}$ in this region was caused by the lack of available GOCI data (less than 20 days in one year). Moreover, relatively fewer observations (approximately five days) were used for training in this region. In addition, Figure $5 \mathrm{c}-\mathrm{h}$ revealed anomalously high or low values of $R^{2}$ in the southeastern part of the study region (the northwest Pacific region). The northwest Pacific region is known to have heavily clouded areas; unsurprisingly, these cloudy conditions led to a lack of observations in this region. The RMSE distribution also shows good agreement of the MPNN model in the ECS (Figure 6c). The reason for the relatively high RMSE near the Changiiang River mouth is that the SSS fluctuated widely over this region (from approximately 1 psu to $35 \mathrm{psu})$.

Finally, the validation with the I-ORS SSS measurement yielded an $\mathrm{R}^{2}$ of 0.92 and an RMSE of 0.30 psu. Because the I-ORS is located between the Changjiang River mouth and Jeju Island, the SSS estimation model accuracy in this area is important to monitor the CDW extension to the Korean coastal region, including Jeju Island. The predicted SSS shows good agreement with the I-ORS data and supports the model accuracy near the I-ORS region. In addition, a sensitivity analysis was conducted to understand the importance of the input parameters for estimating the SSS at the I-ORS site (Figure 8). Each input parameter played a role in the MPNN model. Of these parameters, Rrs660 was associated with relatively high SSS ( $>34 \mathrm{psu}$ ) and Rrs680 was associated with relatively low SSS ( $<28 \mathrm{psu}$ ). The red wavelengths of Rrs are important in this model. This is an important result because many previous studies have estimated the SSS in the coastal region without using the red spectral signal but rather using the blue and green spectral signals $[6,21,23,25-28]$. The relationship between the optical features 
and the SSS differs near the Changjiang River mouth region and Jeju Island because the CDOM or suspended particles can settle with distance from the river mouth. Even if the same CDOM signal is observed at different locations, the SSS is not necessarily the same. Therefore, SSS estimations using simple equations, primarily derived from a CDOM approach, are likely inappropriate for estimating the SSS over wide areas. Red-wavelength signals have been found to be highly related to turbid water in various studies [43-49]. In addition, the chlorophyll concentration (Chl) has been found to be highly linked to the CDW summer distributions during the period of 1998-2007 [4]. Moreover, the red wavelength of the spectrum $(675 \mathrm{~nm})$ is the second peak of the Chl absorption spectra [50]. Therefore, the relationship between $\mathrm{Chl}$ in turbid and fresh water might facilitate the SSS estimation in the MPNN model. However, it is difficult to determine the influence of Chl using only one wavelength signal $(680 \mathrm{~nm})$. Therefore, the importance of Chl for estimating SSS needs to be verified in a future study. In addition, the relationship between the SSS and the red-wavelength signal is not clear. The influence of Chl in the CDW, and its effect on the SSS requires further study. Figure 12 shows the hourly SSS distribution near the Changjiang River mouth region on April 30, 2016.
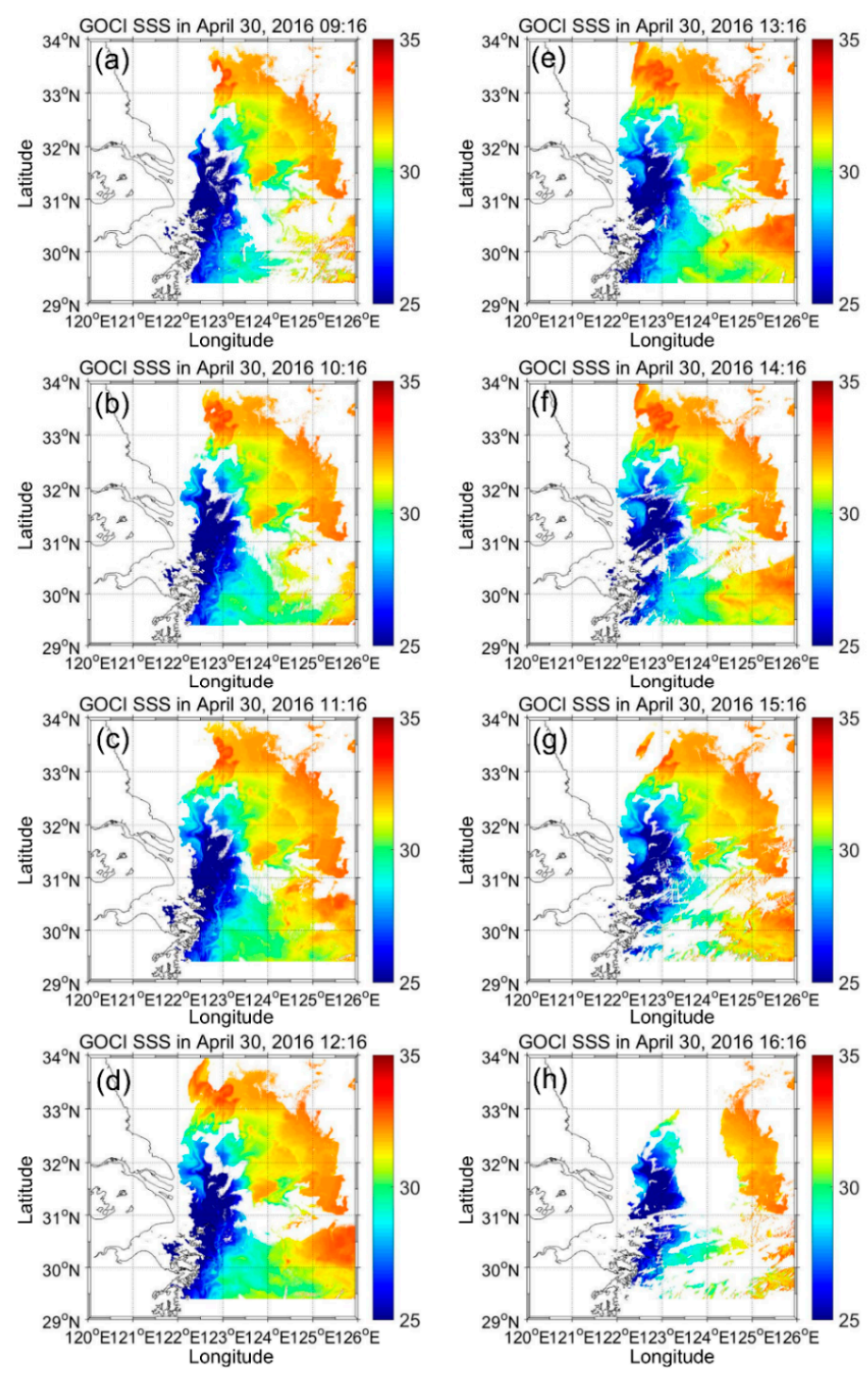

Figure 12. Hourly GOCI SSS distribution in April 30, 2016 at the local time of (a) 09:16, (b) 10:16, (c) 11:16, (d) 12:16, (e) 13:16, (f) 14:16, (g) 15:16, and (h) 16:16. Such hourly GOCI SSS measurements permit the SSS monitoring with high spatial and temporal resolutions. 
In order to estimate hourly GOCI SSS using neural network, SST has to be observed at the same time as the important input as demonstrated in this study. However, such SST measurement from satellite sensor is not available during this study period. For the future hourly SSS estimation using GOCI and SST, hourly SST in the ECS can be used, which has been observed by the Advanced Meteorological Imager (AMI) sensor on Geostationary Earth Orbit (GEO)-Korea Multi-Purpose Satellite (KOMPSAT)-2A. Therefore, hourly SSS can be achieved based on the similar method suggested in this study using the hourly SST data from GEO-KOMPSAT-2A (GK-2A) and ocean color measurements from the GEO-KOMPSAT-2B (GK-2B). The former was launched on December 5, 2018, and the latter was launched February 19, 2020.

\section{Conclusions}

This study is the first attempt to estimate the SSS using GOCI with NN in the ECS. Since CDW volume is large during the summer season, the ocean upper layer in ECS is very stably stratified by low SSS and high SST. The previous studies for estimating SSS in the ECS using CDOM approach, did not consider the relationship between SSS and SST $[6,25,26]$. In this study, SST was used as one of input parameter, and the results indicated that the SST was crucial factor to obtain better SSS estimations. Therefore, the utilization of SST is highly recommended for estimating the coastal salinity using satellite ocean color measurements. Finally, hourly SSS distributions can be estimated using the MPNN model. Figure 12 shows the hourly SSS distribution near the Changiiang River mouth region on April 30, 2016. The eight panels show the continuous SSS distribution over eight hours. Hourly GOCI SSS data can be used for various fields. For example, hourly SSS values will be very useful information are needed to avoid the influence of low SSS at aquaculture sites. Atypical aquaculture site is approximately $2 \mathrm{~km}$ long and coastal water typically moves at approximately $10 \mathrm{~cm} \mathrm{~s}^{-1}$. At this rate, low SSS water would expand an aquaculture site within approximately $5.6 \mathrm{~h}$. With that, aqua farmers may know its spatial trajectories and time to reach their site. In addition, SSS is an important parameter for not only marine physical conditions (e.g., density), but also the marine biogeochemical environment. Therefore, longer time series in the high resolution of SSS data would be useful for understanding CDW itself and its effect on physical-biogeochemical interactions in the ECS.

Author Contributions: Conceptualization, D.-W.K. and Y.-H.J.; methodology, D.-W.K.; software, D.-W.K.; validation, D.-W.K.; formal analysis, D.-W.K.; investigation, D.-W.K.; resources, J.-Y.J.; data curation, D.-W.K.; writing_original draft preparation, D.-W.K.; writing—-review and editing, Y.-H.J., Y.-J.P. and J.-Y.J.; visualization, D.-W.K.; supervision, Y.-H.J.; project administration, Y.-H.J.; funding acquisition, Y.-H.J. All authors have read and agreed to the published version of the manuscript.

Funding: This research was funded by the project titled Technology development for Practical Applications of Multi-Satellite data to maritime issues funded by the Ministry of Oceans and Fisheries, Korea. The project titled "Construction of Ocean Research Station and their Application Studies" funded by the Ministry of Oceans and Fisheries, Korea had provided with the I-ORS data.

Conflicts of Interest: Authors declare no conflict of interest.

\section{References}

1. Chen, C.; Zhu, J.; Beardsley, R.C.; Franks, P.J. Physical-biological sources for dense algal blooms near the Changiiang River. Geophys. Res. Lett. 2003, 30, 1515-1518. [CrossRef]

2. Lee, N.K.; Suh, Y.S.; Kim, Y.S. Satellite remote sensing to monitor seasonal horizontal distribution of resuspended sediments in the East China Sea. J. Korean Assoc. Geogr. Inf. Stud. 2003, 6, 151-161.

3. Moon, J.H.; Pang, I.C.; Yoon, J.H. Response of the Changjiang diluted water around Jeju Island to external forcings: A modeling study of 2002 and 2006. Cont. Shelf Res. 2009, 29, 1549-1564. [CrossRef]

4. Kim, H.C.; Yamaguchi, H.; Yoo, S.; Zhu, J.; Okamura, K.; Kiyomoto, Y.; Tanaka, K.; Kim, S.W.; Park, T.; Ishizaka, J. Distribution of Changjiang diluted water detected by satellite chlorophyll-a and its interannual variation during 1998-2007. J. Oceanogr. 2009, 65, 129-135. [CrossRef]

5. Moon, J.H.; Hirose, N.; Yoon, J.H.; Pang, I.C. Offshore detachment process of the low-salinity water around Changjiang Bank in the East China Sea. J. Phys. Oceanogr. 2010, 40, 1035-1053. [CrossRef] 
6. Bai, Y.; Pan, D.; Cai, W.J.; He, X.; Wang, D.; Tao, B.; Zhu, Q. Remote sensing of salinity from satellite-derived CDOM in the Changjiang River dominated East China Sea. J. Geophys. Res. Ocean. 2013, 118, 227-243. [CrossRef]

7. Kim, S.B.; Lee, J.H.; Matthaeis, P.; Yueh, S.; Hong, C.S.; Lee, J.H.; Lagerloef, G. Sea surface salinity variability in the $\mathrm{E}$ ast $\mathrm{C}$ hina $\mathrm{S}$ ea observed by the A quarius instrument. J. Geophys. Res. Ocean. 2014, 119, 7016-7028. [CrossRef]

8. Lee, D.K.; Kwon, J.I.; Son, S. Horizontal distribution of Changjiang Diluted Water in summer inferred from total suspended sediment in the Yellow Sea and East China Sea. Acta Oceanol. Sin. 2015, 34, 44-50. [CrossRef]

9. Moon, J.-H.; Kim, T.; Son, Y.B.; Hong, J.-S.; Lee, J.-H.; Chang, P.-H.; Kim, S.-K. Contribution of low-salinity water to sea surface warming in the summer of 2016. Prog. Oceanogr. 2019, 175, 68-88.

10. Suh, Y.S.; Jang, L.H.; Lee, N.K. Detection of low salinity water in the northern East China Sea during summer using ocean color remote sensing. Korean J. Remote Sens. 2004, 20, 153-162. (in Korean).

11. Yoon, H.J.; Cho, H.K. A study on the diluted water from the Yangtze River in the East China Sea using satellite data. J. Korean Assoc. Geogr. Inf. Stud. 2005, 8, 33-43. (in Korean).

12. Zhou, F.; Xuan, J.L.; Ni, X.B.; Huang, D.J. A preliminary study of variations of the Changjiang Diluted Water between August of 1999 and 2006. Acta Oceanol. Sin. 2009, 28, 1-11.

13. KHOA. High sea temperature phenomenon of August 2016. In Unusual ocean analysis report; KHOA (Korea Hydrographic and Oceanographic Agency): Busan, Republic of Korea, 2016; Volume 1. (in Korean)

14. Koblinsky, C.J.; Hildebrand, P.; LeVine, D.; Pellerano, F.; Chao, Y.; Wilson, W.; Yueh, S.; Lagerloef, G. Sea surface salinity from space: Science goals and measurement approach. Radio Sci. 2003, 38. [CrossRef]

15. Entekhabi, D.; Njoku, E.G.; O’Neill, P.E.; Kellogg, K.H.; Crow, W.T.; Edelstein, W.N.; Kimball, J. The soil moisture active passive (SMAP) mission. Proc. IEEE 2010, 98, 704-716. [CrossRef]

16. Font, J.; Camps, A.; Borges, A.; Martín-Neira, M.; Boutin, J.; Reul, N.; Kerr, Y.H.; Hahne, A.; Mecklenburg, S. SMOS: The challenging sea surface salinity measurement from space. Proc. IEEE 2009, 98, 649-665. [CrossRef]

17. Kerr, Y.H.; Waldteufel, P.; Wigneron, J.P.; Delwart, S.; Cabot, F.; Boutin, J.; Escorihuela, M.J.; Font, J.; Reul, N.; Juglea, S.E.; et al. The SMOS mission: New tool for monitoring key elements of the global water cycle. Proc. IEEE 2010, 98, 666-687. [CrossRef]

18. Geiger, E.F.; Grossi, M.D.; Trembanis, A.C.; Kohut, J.T.; Oliver, M.J. Satellite-derived coastal ocean and estuarine salinity in the Mid-Atlantic. Cont. Shelf Res. 2013, 63, S235-S242. [CrossRef]

19. Chen, S.; Hu, C. Estimating sea surface salinity in the northern Gulf of Mexico from satellite ocean color measurements. Remote Sens. Environ. 2017, 201, 115-132. [CrossRef]

20. Mohammed, P.N.; Aksoy, M.; Piepmeier, J.R.; Johnson, J.T.; Bringer, A. SMAP L-band microwave radiometer: RFI mitigation prelaunch analysis and first year on-orbit observations. IEEE Trans. Geosci. Remote. Sens. 2016, 54, 6035-6047. [CrossRef]

21. Nakada, S.; Kobayashi, S.; Hayashi, M.; Ishizaka, J.; Akiyama, S.; Fuchi, M.; Nakajima, M. High-resolution surface salinity maps in coastal oceans based on geostationary ocean color images: quantitative analysis of river plume dynamics. J. Oceanogr. 2018, 74, 287-304. [CrossRef]

22. Chen, R.F. In situ fluorescence measurements in coastal waters. Org. Geochem. 1999, 30, 397-409. [CrossRef]

23. Binding, C.E.; Bowers, D.G. Measuring the salinity of the Clyde Sea from remotely sensed ocean colour. Estuar. Coast. Shelf Sci. 2003, 57, 605-611. [CrossRef]

24. Del Vecchio, R.; Blough, N.V. Spatial and seasonal distribution of chromophoric dissolved organic matter and dissolved organic carbon in the Middle Atlantic Bight. Mar. Chem. 2004, 89, 169-187. [CrossRef]

25. Sasaki, H.; Siswanto, E.; Nishiuchi, K.; Tanaka, K.; Hasegawa, T.; Ishizaka, J. Mapping the low salinity Changjiang Diluted Water using satellite-retrieved colored dissolved organic matter (CDOM) in the East China Sea during high river flow season. Geophys. Res. Lett. 2008, 35. [CrossRef]

26. Ahn, Y.H.; Shanmugam, P.; Moon, J.E.; Ryu, J.H. Satellite remote sensing of a low-salinity water plume in the East China Sea. Ann. Geophys. Atmos. Hydrospheres Space Sci. 2008, 26, 2019-2035. [CrossRef]

27. Liu, R.; Zhang, J.; Yao, H.; Cui, T.; Wang, N.; Zhang, Y.; An, J. Hourly changes in sea surface salinity in coastal waters recorded by Geostationary Ocean Color Imager. Estuarine Coast. Shelf Sci. 2017, 196, 227-236. [CrossRef] 
28. Sun, D.; Su, X.; Qiu, Z.; Wang, S.; Mao, Z.; He, Y. Remote Sensing Estimation of Sea Surface Salinity from GOCI Measurements in the Southern Yellow Sea. Remote Sens. 2019, 11, 775. [CrossRef]

29. Hu, C.; Muller-Karger, F.E.; Biggs, D.C.; Carder, K.L.; Nababan, B.; Nadeau, D.; Vanderbloemen, J. Comparison of ship and satellite bio-optical measurements on the continental margin of the NE Gulf of Mexico. Int. J. Remote Sens. 2003, 24, 2597-2612. [CrossRef]

30. Choi, J.K.; Park, Y.J.; Ahn, J.H.; Lim, H.S.; Eom, J.; Ryu, J.H. GOCI, the world's first geostationary ocean color observation satellite, for the monitoring of temporal variability in coastal water turbidity. J. Geophys. Res. Ocean. 2012, 117. [CrossRef]

31. Doxaran, D.; Lamquin, N.; Park, Y.J.; Mazeran, C.; Ryu, J.H.; Wang, M.; Poteau, A. Retrieval of the seawater reflectance for suspended solids monitoring in the East China Sea using MODIS, MERIS and GOCI satellite data. Remote Sens. Environ. 2014, 146, 36-48. [CrossRef]

32. Son, Y.B.; Gardner, W.D.; Richardson, M.J.; Ishizaka, J.; Ryu, J.H.; Kim, S.H.; Lee, S.H. Tracing offshore low-salinity plumes in the Northeastern Gulf of Mexico during the summer season by use of multispectral remote-sensing data. J. Oceanogr. 2012, 68, 743-760. [CrossRef]

33. O’Reilly, J.E.; Maritorena, S.; Mitchell, B.G.; Siegel, D.A.; Carder, K.L.; Garver, S.A.; Kahru, M.; McClain, C. Ocean color chlorophyll algorithms for SeaWiFS. J. Geophys. Res. Ocean. 1998, 103, 24937-24953. [CrossRef]

34. Ryu, J.H.; Han, H.J.; Cho, S.; Park, Y.J.; Ahn, Y.H. Overview of geostationary ocean color imager (GOCI) and GOCI data processing system (GDPS). Ocean Sci. J. 2012, 47, 223-233. [CrossRef]

35. Lie, H.J.; Cho, C.H.; Lee, J.H.; Lee, S. Structure and eastward extension of the Changjiang River plume in the East China Sea. J. Geophys. Res. Ocean. 2003, 108. [CrossRef]

36. Ha, K.J.; Nam, S.; Jeong, J.Y.; Moon, I.J.; Lee, M.; Yun, J.; Jang, C.J.; Kim, Y.S.; Byun, D.S.; Shim, J.S.; et al. Observations utilizing Korean Ocean Research Stations and their Applications for Process Studies. Bull. Am. Meteorol. Soc. 2019, 100, 2061-2075. [CrossRef]

37. Wu, Q.; Wang, X.; He, X.; Liang, W. Validation and Application of SMAP SSS Observation in Chinese Coastal Seas. In Coastal Environment, Disaster, and Infrastructure-A Case Study of China's Coastline; Liang, X.S., Zhang, Y., Eds.; IntechOpen: London, UK, 2018; pp. 273-284.

38. Lee, M.S.; Park, K.A.; Moon, J.E.; Kim, W.; Park, Y.J. Spatial and temporal characteristics and removal methodology of suspended particulate matter speckles from Geostationary Ocean Color Imager data. Int. J. Remote Sens. 2019, 40, 3808-3834. [CrossRef]

39. Wei, J.; Lee, Z.; Shang, S. A system to measure the data quality of spectral remote-sensing reflectance of aquatic environments. J. Geophys. Res. Ocean. 2016, 121, 8189-8207. [CrossRef]

40. Kingma, D.P.; Ba, J. Adam: A method for stochastic optimization. arXiv 2014, arXiv:1412.6980.

41. Moh, T.; Cho, J.H.; Jung, S.K.; Kim, S.H.; Son, Y.B. Monitoring of the Changjiang River Plume in the East China Sea using a Wave Glider. J. Coast. Res. 2018, 85 (sp1), 26-30. [CrossRef]

42. Beardsley, R.C.; Limeburner, R.; Yu, H.; Cannon, G.A. Discharge of the Changjiang (Yangtze river) into the East China sea. Cont. Shelf Res. 1985, 4, 57-76. [CrossRef]

43. Gitelson, A.A.; Schalles, J.F.; Hladik, C.M. Remote chlorophyll-a retrieval in turbid, productive estuaries: Chesapeake Bay case study. Remote Sens. Environ. 2007, 109, 464-472. [CrossRef]

44. Shi, W.; Wang, M. Satellite observations of flood-driven Mississippi River plume in the spring of 2008. Geophys. Res. Lett. 2009, 36. [CrossRef]

45. Shen, F.; Verhoef, W.; Zhou, Y.; Salama, M.S.; Liu, X. Satellite estimates of wide-range suspended sediment concentrations in Changjiang (Yangtze) estuary using MERIS data. Estuaries Coasts 2010, 33, 1420-1429. [CrossRef]

46. Zhang, M.; Tang, J.; Dong, Q.; Song, Q.; Ding, J. Retrieval of total suspended matter concentration in the Yellow and East China Seas from MODIS imagery. Remote Sens. Environ. 2010, 114, 392-403. [CrossRef]

47. Son, S.; Wang, M.; Shon, J.K. Satellite observations of optical and biological properties in the Korean dump site of the Yellow Sea. Remote Sens. Environ. 2011, 115, 562-572. [CrossRef]

48. Son, S.; Wang, M. Water properties in Chesapeake Bay from MODIS-Aqua measurements. Remote Sens. Environ. 2012, 123, 163-174. [CrossRef] 
49. Shi, W.; Wang, M. Ocean reflectance spectra at the red, near-infrared, and shortwave infrared from highly turbid waters: A study in the Bohai Sea, Yellow Sea, and East China Sea. Limnol. Oceanogr. 2014, 59, 427-444. [CrossRef]

50. Bricaud, A.; Claustre, H.; Ras, J.; Oubelkheir, K. Natural variability of phytoplanktonic absorption in oceanic waters: Influence of the size structure of algal populations. J. Geophys. Res. Ocean. 2004, 109. [CrossRef]

(C) 2020 by the authors. Licensee MDPI, Basel, Switzerland. This article is an open access article distributed under the terms and conditions of the Creative Commons Attribution (CC BY) license (http://creativecommons.org/licenses/by/4.0/). 